\title{
EFEITO DO TIPO DE SISTEMA DE CRIAÇÃO NOS RESULTADOS ECONÔMICOS DE SISTEMAS DE PRODUÇÃO DE LEITE NA REGIÃO DE LAVRAS (MG) ${ }^{1}$
}

\author{
Effect of the type of breeding system on the economical \\ results of milk production systems in Lavras region (MG)
}

\author{
Marcos Aurélio Lopes², André Luis Ribeiro Lima ${ }^{3}$, Francisval de Melo Carvalho ${ }^{4}$, \\ Ricardo Pereira Reis ${ }^{4}$, Íris Cristina Santos ${ }^{5}$, Fernanda Helena Saraiva ${ }^{6}$
}

\section{RESUMO}

Objetivou-se com esta pesquisa estudar a rentabilidade da atividade leiteira de sistemas de produção de leite na região de Lavras/MG, analisando a influência do tipo do sistema de criação sobre o custo de produção do leite. Pretendeu-se, ainda, identificar os componentes que exerceram maior influência sobre os custos finais da atividade e também o ponto de equilíbrio. Os dados utilizados foram provenientes de 16 sistemas de produção alocados em um de três tipos de sistemas de criação (em regime de pastejo, semiconfinado e confinado), localizados na região de Lavras, coletados mensalmente durante o período de janeiro de 2002 a junho de 2003. O processamento eletrônico dos dados, bem como a análise de rentabilidade foi realizada pelo software Custo Bovino Leite ${ }^{\circledR}$, considerando a margem bruta, a margem líquida e o resultado (lucro ou prejuízo) como indicadores de eficiência econômica. O tipo do sistema de criação influenciou o custo total de produção do leite e, portanto, a lucratividade e rentabilidade, sendo os sistemas de produção em confinamento os que apresentaram os menores custos unitários. O tipo do sistema de criação influenciou os "pesos” dos itens componentes do custo operacional efetivo da atividade leiteira, sendo esses diferentes em cada um dos três sistemas estudados. Esforços gerenciais e tecnológicos deverão ser feitos, objetivando aumentar a produção média diária, que está muito aquém do ponto de equilíbrio. Na análise econômica, por apresentar margem líquida positiva e o resultado econômico negativo, nos três tipos de sistemas de criação, conclui-se que a atividade leiteira tem condições de produzir em médio prazo; e, em longo prazo, os pecuaristas estão se descapitalizando.

Termos para indexação: Análise de rentabilidade, bovinocultura de leite, custo de produção, sistema de criação, ponto de equilíbrio.

\begin{abstract}
The aim of the research was to study the profitability of dairy business of milk production systems in Lavras region (MG), by surveying the influence of the type of breeding system upon the production cost of milk. In addition, the identification of the components that most influenced the final costs of the business and of the breakeven point were intended. The data utilized came from 16 production systems allocated in one of three types of breeding systems (grazing regimen, semi-feedlot and feedlot) situated in Lavras region, being monthly collected from January 2002 to June 2003. The electronic data processing as well as the profitability analysis were accomplished by the "Custo Bovino Leite" software. The analyses of costs and profitability were performed by taking into consideration gross margin, net margin and the result (profit or loss) as indicators of economical efficiency. The type of breeding system influenced the "weights" of the component items of the effective operational cost of dairy business, these being different in each of the three levels studied. Managerial and technological efforts should be made in order to increase the daily average yield, which is very far from the breakeven point. In the economical analysis, for presenting positive net margin and negative result, in the three types of breeding systems, the conclusion is that milk farmers have conditions to produce in the middle-term. In the long-term, however, milk farmers have been losing money.
\end{abstract}

Index terms: Profitability analysis, dairy cattle, production cost, breeding system, breakeven point.

(Recebido para publicação em 7 de novembro de 2003 e aprovado em 10 de maio de 2004)

1. Projeto (SHA 80276/01) financiado pela FAPEMIG.

2. Professor, DSc., Departamento de Medicina Veterinária da Universidade Federal de Lavras/UFLA - Caixa Postal 3037 - $37200-000$ - Lavras, MG, Telefax: (35)3829-1148; malopes@ufla.br.

3. Acadêmico do curso de Administração da UFLA, bolsista de iniciação científica da FAPEMIG.

4. Professores do Departamento de Administração e Economia da UFLA.

5. Acadêmica do curso de Medicina Veterinária da UFLA, bolsista de iniciação científica da FAPEMIG.

6. Acadêmica do curso de Medicina Veterinária da UFLA, estagiária. 


\section{INTRODUÇÃO}

Diversas transformações, entre outros fatos, têm contribuído para que os produtores de leite reflitam sobre a necessidade de administrarem bem a atividade, tornando-se mais eficientes e, conseqüentemente, competitivos. Nessa nova realidade, ter controle adequado e principalmente um sistema de custo de produção de leite que gere informações para a tomada de decisões rápidas e objetivas são fundamentais para o sucesso da empresa.

O estudo do custo de produção é um dos assuntos mais importantes da microeconomia, pois fornece ao empresário um indicativo para a escolha das linhas de produção a serem adotadas e seguidas, permitindo à empresa dispor e combinar os recursos utilizados na produção, visando a apurar melhores resultados econômicos (REIS, 1999a).

Os dados obtidos da apuração dos custos de produção têm sido utilizados para diferentes finalidades, tais como: estudo da rentabilidade da atividade leiteira; redução dos custos controláveis; planejamento e controle das operações do sistema de produção do leite; identificação e determinação da rentabilidade do produto; identificação do ponto de equilíbrio do sistema de produção de leite; e instrumento de apoio ao produtor no processo de tomada de decisões seguras e corretas (LOPES e CARVALHO, 2000).

A necessidade de analisar economicamente a atividade leiteira é importante, pois, com isso, o produtor passa a conhecer e utilizar, de maneira inteligente e econômica, os fatores de produção (terra, trabalho e capital). A partir daí, localiza os pontos de estrangulamento para depois concentrar esforços gerenciais e/ou tecnológicos para obter sucesso na sua atividade e atingir os seus objetivos de maximização de lucros ou minimização de custos (LOPES e CARVALHO, 2000).

Vários pesquisadores têm se preocupado em estimar o custo de produção e estudar a viabilidade econômica da produção de leite (GOMES et al., 1989; PRADO et al., 1995; SEBRAE-MG/FAEMG, 1996; FABRI JÚNIOR, 1996; MARQUES, 1999; BENEDETTI et al., 2000; PEREIRA et al., 2002; MANZANO et al., 2002; ESTEVES et al., 2002; MARTINS et al., 2002). Entretanto, esses pesquisadores não mostraram quais fatores influenciaram 0 custo, quais componentes exerceram maior influência e nem mesmo identificaram o ponto de equilíbrio dos sistemas de produção do leite. Entre os fatores que podem influenciar o custo de produção, está o tipode sistema de criação, se em regime de pastejo, semiconfinado ou confinado.

Realizou-se esta pesquisa objetivando estudar a rentabilidade da atividade leiteira de sistemas de produção de leite na região de Lavras/MG, analisando a influência do tipo do sistema de criação sobre o custo de produção do leite. Pretendeu-se, ainda, identificar os componentes que exerceram maior influência sobre os custos finais da atividade e identificar o ponto de equilíbrio.

\section{MATERIAL E MÉTODOS}

Os dados utilizados no presente estudo foram provenientes de 16 sistemas de produção de leite localizados na região de Lavras, sul do Estado de Minas Gerais, coletados durante o período de janeiro de 2002 a junho de 2003.

Nesta pesquisa foram consideradas duas etapas diferentes no levantamento das informações. Em uma etapa, utilizando-se um questionário e caderneta de campo, foi realizado o inventário completo dos bens das propriedades estudadas, apurando valor e vida útil de cada ativo, sendo, posteriormente, alocados em um dos seguintes grupos: benfeitorias, máquinas, veículos, equipamentos e implementos, ferramentas e rebanho. Nas situações nas quais o pecuarista não dispunha de informações referentes ao valor e data de aquisição, para a estimativa dos valores atuais, bem como da vida útil restante, foi adotado o seguinte critério: os bens foram analisados e, em função do estado de conservação, foram enquadrados em um dos seguintes escores: ótimo, bom, regular e ruim. Para os bens em ótimo, bom, regular e ruim estado de conservação, os valores atuais foram estimados em 100, 75, 50 e $25 \%$, respectivamente, dos valores de mercados dos bens novos. Para a estimativa de vida útil restante, consideraram-se os percentuais de 100, 75, 50 e 25, para os bens em ótimo, bom, regular e ruim estado de conservação.

Quanto às benfeitorias, cada uma foi medida, sendo atribuído um estado de conservação, objetivando auxiliar na estimativa do valor atual. Em função da área, do estado de conservação e do padrão de acabamento, foi estimado um valor por $\mathrm{m}^{2}$ de construção. $\mathrm{O}$ valor atual utilizado foi produto do valor do $\mathrm{m}^{2}$ pela área da benfeitoria.

Na outra etapa, as propriedades foram visitadas no início de cada mês para coleta de dados referentes às produções, despesas realizadas e receitas apuradas no mês anterior. A coleta de dados deu-se em cadernetas de 
campo especificamente preparadas para esse fim. $\mathrm{Na}$ Universidade Federal de Lavras, tais dados foram cadastrados no software Custo Bovino Leite ${ }^{\circledR}$ (LOPES et al., 2002a), aplicativo esse utilizado para o processamento eletrônico dos dados, bem como na análise de rentabilidade dos sistemas de produção. Tal software contemplou as duas estruturas de custo de produção: Custo Total de Produção, que envolve o custo fixo e variável, utilizado por Reis (1999b) e Custo Operacional, proposto por Matsunaga et al. (1976).

Os itens que compõem o custo operacional efetivo de produção do leite foram divididos em grupos: mão-de-obra, alimentação, sanidade, reprodução, ordenha, impostos e despesas diversas (LOPES e LOPES, 1999). Nesta pesquisa, as despesas referentes à energia elétrica e combustíveis foram separadas do grupo despesas diversas, sendo, então, computadas separadamente.

Para evitar duplicidade de lançamento de despesas, a análise não considerou a depreciação de matrizes, uma vez que o sistema avalia o custo de produção da atividade como um todo e os custos de cria e recria de fêmeas de reposição, assim como os de manutenção de vacas secas também foram contemplados pela mesma.

Visando à análise da influência do tipo de sistema de criação sobre o custo de produção do leite, os 16 sistemas de produção foram alocados em um dos três tipos de sistemas de criação: em regime de pastejo, semiconfinado ou confinado, cada qual com seis, oito e dois sistemas de produção, respectivamente.

A alocação de cada sistema de produção, quanto ao tipo de sistema de criação, foi realizada, principalmente, em função da alimentação dos animais lactantes. Nos sistemas de produção em regime de pastejo, durante a estação seca do ano, os animais receberam, no cocho, a alimentação concentrada na proporção de $1 \mathrm{~kg}$ de ração para cada 3 a 4 kg de leite, bem como a alimentação volumosa, que, em alguns sistemas de produção, foi silagem de milho (Zea mays, L.), em outros, cana-deaçúcar (Sacharum oficcinarum, Linn) e/ou capimelefante (Pennisetum purpureum, Schum) picados. Os animais tiveram ainda acesso a pastagens, que se encontravam em condições bastante precárias, com praticamente nenhuma disponibilidade de alimentos. Na estação chuvosa, os animais foram suplementados com concentrados, nas mesmas proporções da estação seca, e a alimentação volumosa consistiu apenas de pastagens com forrageiras do gênero Brachiaria e/ou nativas (pastagens naturais). Nos sistemas de produção em semiconfinamento, durante a estação seca do ano, os animais receberam, no cocho, a alimentação concentrada na proporção de $1 \mathrm{~kg}$ de ração para cada $3 \mathrm{~kg}$ de leite, bem como a alimentação volumosa, que, em alguns sistemas de produção, foi silagem de milho (Z. mays, $L$ ), em outros, cana-de-açúcar (S. oficcinarum, Linn) e/ou capimelefante (Pennisetum purpureum, Schum) picados. Os animais tiveram ainda acesso a pastagens com pouca disponibilidade de forrageiras do gênero Brachiaria e/ou nativas (pastagens naturais). Na estação chuvosa, os animais eram suplementados com concentrados, nas mesmas proporções da estação seca, e com alimentação volumosa, durante ou logo após as ordenhas. No restante do dia, tinham acesso às mesmas pastagens, sendo dessa vez com disponibilidade de forrageiras o suficiente para não ocorrer superpastejo. Nos sistemas de produção em confinamento, durante todo o ano, os animais receberam, no cocho, a alimentação concentrada na proporção de $1 \mathrm{~kg}$ de ração para cada $3 \mathrm{~kg}$ de leite, bem como a alimentação volumosa (silagem de milho, Zea mays). Os animais tiveram ainda acesso a pastagens com pouca disponibilidade de forrageiras do gênero Brachiaria.

Os índices produtivos e econômicos foram comparados por meio de análises descritivas, utilizando o aplicativo MS Excel ${ }^{\circledR}$, e agrupados em tabelas, objetivando uma melhor comparação, discussão e apresentação dos resultados.

\section{RESULTADOS E DISCUSSÃO}

Um resumo dos recursos disponíveis em 16 sistemas de produção da região de Lavras, MG, agrupados em função do tipo de sistema de criação, do período de janeiro de 2002 a junho de 2003, é apresentado na Tabela 1 . Tais recursos foram úteis nas análises e discussões dos resultados encontrados nesta pesquisa. Na Tabela 2 pode ser observado um resumo da análise de rentabilidade da atividade leiteira desses sistemas de produção. Pelos valores de desvio-padrão, pode-se constatar que os sistemas estudados foram bem diferentes entre si.

A receita total durante o período de estudo foi de $\mathrm{R} \$ 29.184,03$; $\mathrm{R} \$ 59.199,26$ e $\mathrm{R} \$ 357.668,07$, o que correspondeu à soma dos valores apurados com a venda de leite $(79,17 ; 91,92$; e $90,31 \%)$, animais $(20,11 ; 7,40$; e $9,70 \%)$ e subprodutos $(0,72 ; 0,68$; e 0,00\%), para sistemas de criação em pastejo, semiconfinado e confinado, respectivamente (Tabela 3). As diferenças existentes entre os três sistemas de criação podem ser explicadas em função das quantidades de leite produzidas, pois, neste estudo, as maiores produções, coincidentemente, foram as dos sistemas de produção em confinamento. Os sistemas de 
produção em regime de pastejo comercializaram animais mais do que o dobro, quando comparados com os semiconfinados e confinados. Quanto à venda de subprodutos (esterco), 75\%, 66\% e 100\% dos sistemas de produção em regime de pastejo, semiconfinados e confinados, respectivamente, não o comercializaram, justificando as pequenas contribuições na receita bruta. Em todos os sistemas de produção, pelo menos parte desse subproduto foi utilizado como adubo orgânico em capineiras. $O$ fato de ele ser utilizado no próprio sistema de produção, embora em um primeiro momento signifique redução da receita, representou também uma redução nas despesas com manutenção das capineiras. Nas visitas às propriedades, foi observado que há bastante desperdício desse subproduto, em razão das condições inadequadas de armazenamento. Tal fato pode também justificar a pequena comercialização e conseqüente diminuição da rentabilidade.

Na Tabela 4 podem ser observados alguns índices técnicos/gerenciais. As produtividades de leite por ha/ano de $2.789,92 \mathrm{~kg}$ e $1.622,58 \mathrm{~kg}$ nos sistemas de produção em regime de pastejo, e semiconfinados, respectivamente, são muito pequenas, quando comparadas aos $6.057,37 \mathrm{~kg}$ obtidos pelos sistemas confinados e às citadas por Gomes (1997), Schiffler et al. (1999) e Lopes et al. (2001). Por meio desses índices obtidos pelos sistemas de produção em regime de pastejo e semiconfinados, aliados aos das quantidades de matrizes por ha (1,13 e 0,47 , respectivamente), evidencia-se que as áreas estão com suas capacidades produtivas ociosas, principalmente nos sistemas de produção em regime de pastejo e semi-confinados. As produções médias diárias de leite foram de 111,18; 268,85; e 1.421,65 kg, com uma produtividade de 7,30; 9,65; e 14,28 kg por matriz em lactação, para os sistemas de produção em regime de pastejo, semi-confinados e confinados, respectivamente.

Em quatro sistemas de produção em regime de pastejo, o custo variável médio foi superior ao preço de venda do leite, não permitindo, então, que esses sistemas atingissem o ponto de equilíbrio, o qual, considerando as produções dos outros dois, foi de $79,76 \mathrm{~kg} /$ dia. Nesses, a produção média diária foi de $72,33 \mathrm{~kg}$.

Dos oito sistemas de produção em semiconfinamento, em apenas um o custo variável médio foi superior ao preço de venda do leite, não permitindo, então, que esse sistema atingisse o ponto de equilíbrio, o qual, considerando as produções dos outros sete, foi de 3.380,91 kg. Nesses, a produção média diária foi de 260,89 kg. No grupo confinados, em um dos dois sistemas de produção o custo variável médio foi inferior ao preço de venda do leite, e o ponto de equilíbrio foi de $1.010,62 \mathrm{~kg} /$ dia. Nesse, a produção média diária foi de 718,72 kg. Com esses índices evidencia-se que muitos esforços gerenciais e até mesmo tecnológicos devam ser feitos, objetivando aumentar as médias diárias de leite, principalmente nos sistemas de produção em semiconfinamento e confinamento, sem, contudo, aumentar o custo variável médio que, uma vez majorado, aumentará ainda mais o ponto de equilíbrio. Uma alternativa é aumentar a eficiência produtiva, ou seja, a produtividade por matriz, otimizando, assim, as despesas com mão-de-obra, medicamentos, inseminação artificial, impostos fixos, energia e outros. Tais despesas, aumentando-se a produtividade por matriz, não serão majoradas.

TABELA 1 - Recursos disponíveis em 16 sistemas de produção agrupados em função do tipo de sistema de criação, (período de 18 meses).

\begin{tabular}{|c|c|c|c|c|c|c|}
\hline \multirow{2}{*}{$\begin{array}{r}\text { Sistema de Criação } \\
\text { crição }\end{array}$} & \multicolumn{2}{|c|}{ Pastejo } & \multicolumn{2}{|c|}{ Semiconfinado } & \multicolumn{2}{|c|}{ Confinado } \\
\hline & Média & DP & Média & DP & Média & DP \\
\hline Valor do patrimônio sem terra (R\$) & $46.904,73$ & $37.478,88$ & $78.359,14$ & $28.203,45$ & $130.792,50$ & 14661,86 \\
\hline Valor do patrimônio em terra (R\$) & $83.248,67$ & $108.184,39$ & $178.692,75$ & $131.764,53$ & $356.000,00$ & 33941,13 \\
\hline Área (ha) & 26,83 & 36,36 & 81,38 & 50,47 & 89,00 & 8,49 \\
\hline $\begin{array}{l}\text { Quantidade de animais em lactação/dia } \\
\text { (matrizes) }\end{array}$ & 15,00 & 5,76 & 27,75 & 8,22 & 100,00 & 70,71 \\
\hline Mão-de-obra (quantidade de serviços/dia) & 1,17 & 0,41 & 1,94 & 0,78 & 5,00 & 1,41 \\
\hline
\end{tabular}

DP = Desvio-Padrão

Ciênc. agrotec., Lavras, v. 28, n. 5, p. 1177-1189, set.out., 2004 
Efeito do tipo de sistema de criação nos resultados econômicos de sistemas de...

1181

TABELA 2 - Resumo da análise de rentabilidade da atividade leiteira de 16 sistemas de produção agrupados em função do tipo de sistema de criação, em R\$ (período de 18 meses).

\begin{tabular}{|c|c|c|c|c|c|c|}
\hline \multirow{2}{*}{$\begin{array}{c}\text { Sistema de Criação } \\
\text { Descrição }\end{array}$} & \multicolumn{2}{|c|}{ Pastejo } & \multicolumn{2}{|c|}{ Semiconfinado } & \multicolumn{2}{|c|}{ Confinado } \\
\hline & Média & DP & Média & DP & Média & DP \\
\hline Receitas & $29.184,03$ & $13.456,50$ & $59.199,26$ & $17.781,26$ & $357.668,07$ & 218021,46 \\
\hline Leite (R\$) & 23.186,71 & $12.185,17$ & $54.882,61$ & $17.544,11$ & $332.789,30$ & 229029,08 \\
\hline Animais (R\$) & $5.690,09$ & $3.742,39$ & $3.984,00$ & $2.305,33$ & $24.878,77$ & 11007,62 \\
\hline Subprodutos (R\$) & 306,39 & 623,78 & 332,65 & 729,32 & 0,00 & 0,00 \\
\hline Custo operacional total (COT) & $28.411,86$ & $17.301,90$ & $57.393,96$ & $20.235,52$ & 339.181,82 & 269954,84 \\
\hline Custo operacional efetivo (COE) & $20.524,19$ & $15.266,42$ & $44.868,23$ & $17.393,69$ & $323.403,63$ & 272410,71 \\
\hline Custo com depreciação & $4.377,67$ & $3.451,18$ & $8.520,73$ & $4.834,55$ & $15.778,19$ & 2455,87 \\
\hline Mão-de-obra familiar & $3.510,00$ & $1.883,56$ & $4.005,00$ & $1.829,96$ & 0,00 & 0,00 \\
\hline Custo total (CT) & $38.454,67$ & $25.646,04$ & 79.648,93 & $26.550,42$ & $378.381,16$ & 274470,03 \\
\hline Custos fixos (CF) & $14.173,53$ & $14.806,04$ & $30.117,00$ & $13.101,16$ & $48.438,71$ & 3141,17 \\
\hline Remuneração da terra & $5.435,35$ & $8.036,63$ & $15.067,24$ & $8.096,72$ & $20.537,02$ & 2353,93 \\
\hline Remuneração do capital investido & $4.132,79$ & $3.464,51$ & $6.218,83$ & $2.314,36$ & $11.771,33$ & 1319,57 \\
\hline Remuneração do empresário & 0,00 & 0,00 & 0,00 & 0,00 & 0,00 & 0,00 \\
\hline Impostos & 227,72 & 131,09 & 310,21 & 161,83 & 352,18 & 349,06 \\
\hline Depreciação & $4.377,67$ & $3.451,18$ & $8.520,73$ & $4.834,55$ & $15.778,19$ & 2455,87 \\
\hline Custos variáveis (CV) & $24.281,14$ & $15.063,12$ & $49.531,93$ & $17.801,08$ & $329.942,46$ & 277611,20 \\
\hline Custo operacional efetivo (s/impostos) & $20.296,47$ & $15.190,42$ & $44.558,02$ & $17.338,90$ & $323.051,46$ & 272061,65 \\
\hline Mão-de-obra familiar & $3.510,00$ & $1.883,56$ & $4.005,00$ & $1.829,96$ & 0,00 & 0,00 \\
\hline Remuneração do capital de giro & 474,68 & 322,34 & 968,91 & 422,25 & $6.891,00$ & 5549,56 \\
\hline Margem bruta & $8.659,84$ & $6.695,71$ & $14.331,03$ & $10.733,08$ & $34.264,44$ & 54389,25 \\
\hline Margem líquida & 772,17 & $8.335,23$ & $1.805,30$ & $11.187,54$ & $18.486,25$ & 51933,37 \\
\hline Resultado (lucro ou prejuízo) & $(9.270,64)$ & $17.834,14$ & $(20.449,67)$ & $14.695,20$ & $(20.713,10)$ & 56448,57 \\
\hline Margem bruta / kg leite & 0,19 & 0,16 & 0,11 & 0,07 & 0,09 & 0,13 \\
\hline Margem líquida / kg leite & 0,03 & 0,14 & 0,01 & 0,07 & 0,06 & 0,11 \\
\hline Resultado (lucro ou prejuízo) / kg leite & $(0,13)$ & 0,26 & $(0,15)$ & 0,09 & $(0,00)$ & 0,07 \\
\hline Lucratividade (\%) & $-27,47 \%$ & $54,57 \%$ & $-36,46 \%$ & $21,47 \%$ & $-1,20 \%$ & $15,05 \%$ \\
\hline Rentabilidade (\%) & $2,35 \%$ & $9,97 \%$ & $-5,51 \%$ & $3,66 \%$ & $-1,55 \%$ & $6,48 \%$ \\
\hline Quantidade de leite (kg) & $60.924,47$ & $31.295,26$ & $140.013,50$ & $46.164,21$ & $779.063,50$ & 543741,78 \\
\hline
\end{tabular}

DP = Desvio-Padrão

Ciênc. agrotec., Lavras, v. 28, n. 5, p. 1177-1189, set.out., 2004 
LOPES, M. A. et al.

TABELA 3 - Contribuição de cada item na receita em 16 sistemas de produção agrupados em função do sistema de criação, em \% (período de 18 meses).

\begin{tabular}{lcccccc}
\hline \multicolumn{1}{c}{ Sistema de Criação } & \multicolumn{2}{c}{ Pastejo } & \multicolumn{2}{c}{ Semiconfinado } & \multicolumn{2}{c}{ Confinado } \\
\cline { 2 - 7 } \multicolumn{1}{c}{ Descrição } & Média (\%) & DP & Média (\%) & DP & Média (\%) & DP \\
\hline Venda de leite & 79,17 & 16,11 & 91,92 & 5,64 & 90,31 & 8,99 \\
Venda de animais & 20,11 & 15,82 & 7,40 & 4,57 & 9,70 & 8,99 \\
Venda de subprodutos & 0,72 & 1,26 & 0,68 & 1,26 & 0,00 & 0,00 \\
\hline
\end{tabular}

DP = Desvio-Padrão

O preço médio recebido por $\mathrm{kg}$ de leite foi de $\mathrm{R} \$$ 0,$38 ; \mathrm{R} \$ 0,39$ e $\mathrm{R} \$ 0,43$, para os sistemas de produção em regime de pastejo, semiconfinados e confinados, respectivamente, evidenciando-se que as empresas compradoras de leite remuneram melhor as maiores quantidades, pois, coincidentemente, os sistemas do grupo confinados foram os maiores produtores. Nesse período, o preço médio praticado no Estado de Minas Gerais foi R\$ 0,40 (EMBRAPA, 2003).

O custo operacional total (COT) de R $\$ 28.411,86$; R\$ 57.393,96; e R\$ 339.181,82, para os sistemas de produção em regime de pastejo, semiconfinados e confinados, respectivamente, foi obtido pela soma do custo operacional efetivo (desembolso), com o custo de depreciação dos bens patrimoniais e com a remuneração da mão-de-obra familiar (Tabela 2). Embora não seja um desembolso, o valor referente à depreciação representa uma reserva de caixa que deveria ser feita para se repor os bens patrimoniais (instalações, equipamentos etc.) ao final de sua vida útil. A receita do período permitiu que essa reserva fosse feita, bem como que a mãode-obra familiar fosse remunerada. Isso significa que, ao final da vida útil do bem, permanecendo constantes as condições atuais, o pecuarista teria recursos monetários para a aquisição de um novo bem substituto, não havendo uma descapitalização em médio prazo.

No presente estudo, a depreciação foi responsável por 15,21; 15,52; e 7,23\% do COT, para os pequenos, médios e grandes sistemas de produção (Tabela 4). Por meio desses resultados, demonstra-se que no sistema de produção em confinamento houve uma maior otimização da estrutura física. Lopes et al. (2001), estudando um sistema de produção em semiconfinamento, com produção média de $240 \mathrm{~kg}$ de leite/dia, constataram que a depreciação representou 17,29\% do COT. Embora na literatura não exista informação sobre qual seria um bom valor para esse indicador técnico, pode-se dizer que a eficiência de utilização dos bens dos patrimônios dos sistemas de produção estudados nesta pesquisa foi superior ao sistema estudado por esses pesquisadores, sob o ponto de vista da metodologia do Custo Operacional (MATSUNAGA et al., 1976).

O custo operacional efetivo de R\$20.524,19; $\mathrm{R} \$ 44.868,23$; $\mathrm{R} \$ 323.403,63$, para os sistemas de produção em regime de pastejo, semiconfinados e confinados, respectivamente, representou o desembolso médio no período de 18 meses, feito por cada pecuarista, para custear a atividade. Os itens que compõem o custo operacional efetivo de produção do leite foram divididos em grupos, cada qual responsável pelos percentuais encontrados na Tabela 5. A divisão das despesas em grupos, de acordo com Lopes e Lopes (1999), permite o monitoramento das despesas do sistema de produção de leite, auxiliando o técnico e o produtor em uma análise mais detalhada.

Quanto à mão-de-obra, o percentual de 16,72 nos sistemas de produção em confinamento está abaixo dos encontrados por Lopes et al. (2002b) (19,85\%) e acima dos obtidos pelos sistemas de produção em regime de pastejo e em semiconfinamento, que foi de 9,87 e 15,16, respectivamente. Parte desse valor pode ser explicada pelo fato de aqueles terem adotado somente mão-deobra contratada; enquanto nestes, em apenas um em cada grupo, a mão-de-obra foi exclusivamente contratada, predominando a mão-de-obra familiar. Assim, diminuiuse o desembolso com mão-de-obra, reduzindo a contratação de pessoal. Essa evidência é corroborada pela baixa relação vaca:homem de 13,33:1 e 15,23:1, para sistemas de produção em regime de pastejo e semiconfinamento, respectivamente, encontrada nesse estudo (Tabela 4). Pois, se a relação é baixa, a contratação de pessoal aumenta, e, conseqüentemente, o percentual de despesas referentes à mão-de-obra tende a aumentar. Lopes et al. (2001), realizando a análise de rentabilidade de um sistema de produção de leite em semiconfinamento, com resultados altamente insatisfatórios, encon- 
traram uma relação vaca:homem de 7:1, sendo a mãode-obra responsável por $25,81 \%$ do total das despesas operacionais efetivas. Jarret (1997) preconizou uma relação vaca:homem de 66:1 e 111:1, para sistemas de produção com 300 e 1000 vacas, respectivamente. O índice de 15,16\% encontrado nos sistemas de produção em semiconfinamento, considerando que as necessida- des de mão-de-obra para arraçoamento dos animais são menores, quando comparada aos sistemas em confinamento, aliado ao fato de que ainda há mão-de-obra familiar em um dos sistemas de produção, evidencia que esse importante componente do custo de produção está subutilizado, caracterizando um ponto de estrangulamento.

TABELA 4 - Índices técnicos/gerenciais em 16 sistemas de produção agrupados em função do tipo de sistema de criação, (período de 18 meses).

\begin{tabular}{lcccccc}
\hline \multicolumn{1}{c}{ Sistema de Criação } & \multicolumn{2}{c}{ Pastejo } & \multicolumn{2}{c}{ Semiconfinado } & \multicolumn{2}{c}{ Confinado } \\
\cline { 2 - 7 } \multicolumn{1}{c}{ Descrição } & Média & DP & Média & DP & Média & DP \\
\hline Depreciação/COT (\%) & 15,21 & 5,58 & 15,52 & 6,87 & 7,23 & 6,48 \\
COE/COT (\%) & 64,89 & 14,92 & 76,68 & 10,02 & 92,77 & 6,48 \\
Mão-de-obra familiar/COT (\%) & 19,90 & 15,64 & 7,80 & 4,36 & 0,00 & 0,00 \\
Custo Fixo/Custo Total (\%) & 33,96 & 12,76 & 38,21 & 10,60 & 17,78 & 13,73 \\
Custo Variável/Custo Total (\%) & 66,04 & 12,76 & 61,79 & 10,60 & 82,22 & 13,73 \\
Depreciação/Custo Total (\%) & 11,17 & 2,12 & 10,92 & 4,47 & 5,98 & 4,99 \\
Produtividade animal/dia (kg de leite) & 7,30 & 1,84 & 9,65 & 1,82 & 14,28 & 0,17 \\
Produção diária (kg de leite) & 111,18 & 57,11 & 268,85 & 85,02 & $1.421,65$ & 992,23 \\
Produção de leite por hectare/ano (kg) & $2.789,92$ & $1.244,39$ & $1.622,58$ & $1.205,95$ & $6.057,37$ & 4650,48 \\
Quantidade de vacas em lactação/ha (matrizes) & 1,13 & 0,70 & 0,47 & 0,29 & 1,17 & 0,91 \\
Produção de leite/mão-de-obra (kg/serviço) & 100,38 & 59,03 & 145,34 & 40,37 & 266,94 & 122,94 \\
Relação Vaca/Homem & 13,33 & 5,47 & 15,23 & 3,77 & 18,75 & 8,84 \\
Ponto de equilíbrio (kg de leite/dia) & 79,76 & & $3.380,91$ & & $1.010,62$ & \\
\hline
\end{tabular}

DP = Desvio-Padrão

TABELA 5 - Contribuição de cada item no custo operacional efetivo de 16 sistemas de produção agrupados em função do sistema de criação, em \% (período de 18 meses).

\begin{tabular}{lcccccc}
\hline \multicolumn{1}{c}{\begin{tabular}{c} 
Sistema de Criação \\
\multicolumn{1}{c}{ Descrição }
\end{tabular}} & Média & DP & Média & DP & Média & DP \\
\hline Mão-de-obra & 9,87 & 14,21 & 15,16 & 7,17 & 16,72 & 0,61 \\
Alimentação & 60,62 & 13,73 & 59,34 & 12,74 & 60,38 & 2,91 \\
Sanidade & 3,91 & 2,19 & 3,83 & 1,78 & 3,02 & 0,67 \\
Inseminação artificial & 0,22 & 0,54 & 0,00 & 0,00 & 1,12 & 0,28 \\
Ordenha & 0,00 & 0,00 & 1,00 & 0,84 & 3,07 & 0,18 \\
Impostos (ITR e IPVA) & 1,25 & 0,91 & 0,70 & 0,39 & 0,10 & 0,03 \\
Energia & 10,78 & 5,60 & 10,72 & 6,15 & 6,04 & 2,95 \\
Despesas diversas & 13,36 & 8,35 & 9,25 & 5,09 & 9,57 & 0,03 \\
Total & 100,00 & 0,01 & 100,00 & 0,01 & 100,00 & 0,00 \\
\hline
\end{tabular}

DP = Desvio-Padrão 
A produção diária de leite por mão-de-obra permanente de 100,38 e 145,34 kg, para sistemas de produção em regime de pastejo e semiconfinamento (Tabela 4) está muito aquém das obtidas por Schiffler et al. (1999) (246,12 kg). Esse índice foi de 266,94 kg, para os sistemas em confinamento.

A alimentação foi responsável por 60,62; 59,34 e $60,38 \%$ das despesas operacionais efetivas dos sistemas de produção em regime de pastejo, semiconfinados e confinados, respectivamente. No último grupo, o valor foi inferior aos 65,38\% encontrados por Lopes et al. (2002b), ao estudarem a rentabilidade de um sistema de produção em confinamento, sugerindo uma maior eficiência nesse quesito. Embora não tenham sido encontrados na literatura resultados de pesquisas científicas apontando um valor para tomar-se como parâmetro, o índice obtido pelo primeiro grupo evidencia uma ineficiência na utilização das pastagens, pois sabe-se que essas são mais baratas, principalmente pelo fato de os próprios animais realizarem a colheita e não haver necessidade de adoção de técnicas de conservação de forragens. Essa ineficiência pode ser constatada também, embora em menor grau, nos sistemas em semiconfinamento, quando comparada com o índice obtido pelos sistemas em confinamento, pois uma parte da alimentação dos animais mantidos em semiconfinamento vem das pastagens.

As despesas com medicamentos representaram 3,91; 3,83; e 3,02 \% do custo operacional efetivo dos sistemas de produção em regime de pastejo, semiconfinados e confinados, respectivamente (Tabela 5).

Quanto às despesas com inseminação artificial (sêmen, nitrogênio líquido, além de outros materiais), o percentual obtido de 0,22 nos sistemas de produção em regime de pastejo está muito baixo pelo fato de apenas um dos seis adotar essa tecnologia, o que pode ser deduzido pelo alto desvio-padrão (Tabela 5). Nenhum dos sistemas de produção em semiconfinamento realizou inseminação artificial durante o período estudado. Nos confinados, o percentual foi de 1,12, sendo superior ao 1,02 relatado por Lopes et al. (2002b).

As despesas com aquisição de soluções pré e pós dipping, detergentes ácidos e alcalinos, papel-toalha, desinfetantes e demais produtos utilizados na ordenha representaram 1,0 e 3,07\% das despesas operacionais efetivas, para os sistemas de produção semiconfinados e confinados, respectivamente. Observa-se que a diferença, em termos percentuais, está muito grande, o que pode ser explicado, pois dois dos oito sistemas de produção em semiconfinamento não tiveram gastos com esses materiais, o que também ocorreu com todos os sistemas de produção em regime de pastejo. Com esses resultados evidencia-se pouca preocupação com a obtenção higiênica do leite por $50 \%$ dos pecuaristas. O valor 3,07 está próximo de 2,88\% obtido por Lopes et al. (2002b).

Impostos considerados fixos como o ITR e IPVA representaram apenas 1,$28 ; 0,70$ e $0,10 \%$ das despesas operacionais efetivas para os sistemas de produção em regime de pastejo, semiconfinados e confinados, respectivamente. Embora esses impostos sejam despesas operacionais, também fazem parte do custo fixo, pois o valor do IPVA do automóvel, por exemplo, independe da quantidade de leite produzida. Assim, tal despesa é mais "diluída” nas maiores produções, justificando os menores percentuais nos grupos semiconfinado e confinado, que, coincidentemente, tiveram as maiores produções.

No grupo energia, o qual representou 10,78; 10,72 e $6,04 \%$, para os sistemas de produção em regime de pastejo, semiconfinados e confinados, respectivamente, foram consideradas as despesas com energia elétrica e combustíveis. Nesta pesquisa, optou-se por monitorar tais componentes, pois eles têm uma importância significativa e, uma vez mensurados, possíveis pontos de estrangulamento poderão ser detectados.

Foram consideradas despesas diversas aquelas que não se enquadraram nos grupos mencionados anteriormente, tais como: frete do leite, taxas e impostos variáveis em função da produção, despesas com manutenção de benfeitorias, máquinas e equipamentos. Os valores encontrados foram de 13,36; 8,35 e 9,57\% para os sistemas de produção em regime de pastejo, semiconfinados e confinados, respectivamente.

O custo total (CT), que representou a soma dos custos fixos (CF) e dos custos variáveis (CV), foi de $\mathrm{R} \$ 38.454,67$; $\mathrm{R} \$ 79.648,93$ e $\mathrm{R} \$ 378.381,16$, para os sistemas de produção em regime de pastejo, semiconfinados e confinados, respectivamente. As diferenças existentes entre os três sistemas de criação podem ser explicadas em razão das quantidades de leite produzidas. Pela subtração do custo total da receita, nos três grupos (Tabela 2) verifica-se que todos os custos variáveis puderam ser pagos, que a reserva referente à depreciação pôde ser realizada, mas o capital investido em bens e terra não foi completamente remunerado. Com tal fato evidencia-se que os sistemas de produção estudados, em média, estão se descapitalizando ao longo do tempo.

Os custos fixos, que são compostos pela remuneração da terra, remuneração do capital investido, remuneração do empresário, impostos considerados fixos (ITR e IPVA) e depreciação do patrimônio totalizaram R\$ 14.173,53; R\$ 30.117,00 e R\$ 48.438,71, nos sistemas de criação em regime de pastejo, semiconfina- 
dos e confinados, respectivamente. Esses custos não representaram desembolso (com exceção dos impostos), mas representam o que a atividade deveria remunerar para ser competitiva com outras atividades econômicas e não descapitalizar o pecuarista ao longo dos anos. Se esses custos não forem contemplados, o pecuarista poderá, em longo prazo, perder o patrimônio e se endividar.

Tais custos fixos, que representaram 33,96; 38,21 e 17,78\% do custo total nos sistemas de criação em regime de pastejo, semiconfinados e confinados, respectivamente, estão altos quando comparados aos 16,08\% encontrados por Almeida Júnior et al. (2002). Com esses resultados evidencia-se que os investimentos certamente encontram-se dimensionados para uma produção de leite muito maior do que a média encontrada, o que não aconteceu nos sistemas confinados, cujos custos fixos representaram 17,78\%.

Os custos variáveis, que são compostos pelo custo operacional efetivo, excetuando impostos considerados fixos (ITR e IPVA), pela remuneração do capital de giro e pela mão-de-obra familiar, totalizaram $\mathrm{R} \$$ 24.281,14; R\$ 49.531,93 e R\$ 329.942,46. As diferenças existentes entre os três tipos de sistemas de criação podem ser explicadas em função das quantidades de leite produzidas.

Observa-se pelos indicadores de eficiência econômica: margem bruta (receita bruta menos custo operacional efetivo) e líquida (receita bruta menos o custo operacional total) que tais resultados foram satisfatórios (positivos), evidenciando que a atividade leiteira, nos diferentes tipos de sistema de criação, tem condições de sobreviver em curto e médio prazo, respectivamente. Quando se analisa pelo indicador de eficiência econômica resultado (receita bruta menos custo total), os resultados foram insatisfatórios, evidenciando que a atividade leiteira não conseguiu remunerar o capital em nenhum dos três sistemas de criação (Tabela 2).

Dos seis sistemas de produção em regime de pastejo, nenhum teve margem bruta negativa, evidenciando que o que foi apurado com a venda de leite, animais e subprodutos (esterco) foi suficiente para cobrir as despesas operacionais efetivas (alimentação, mão-de-obra, sanidade etc). Em quatro, a margem líquida foi negativa, sendo, então, a receita suficiente para cobrir as despesas operacionais, mas não para fazer as reservas necessárias para substituição dos bens ao término de suas vidas úteis (depreciação), estando, portanto, os produtores descapitalizando-se a cada ciclo produtivo. Em apenas um, o resultado foi positivo, evidenciando que além de cobrir todas as despesas, o empresário conseguiu remunerar o capital em níveis acima da caderneta de poupança, não se descapitalizando.

Dos oito sistemas de produção em semiconfinamento, apenas um teve margem bruta negativa, evidenciando que o que foi apurado com a venda de leite, animais e subprodutos (esterco) não foi suficiente para cobrir as despesas operacionais efetivas. Em três, a margem líquida foi negativa, sendo a receita suficiente para cobrir as despesas operacionais efetivas, mas não para fazer as reservas necessárias para substituição dos bens ao término de suas vidas úteis (depreciação), estando, portanto, os produtores descapitalizando-se a cada ciclo produtivo. Em apenas um, o resultado foi positivo, evidenciando que além cobrir todas as despesas, o empresário conseguiu remunerar o capital em níveis acima da caderneta de poupança, não se descapitalizando.

Dos dois sistemas de produção em confinamento, um obteve margem bruta, líquida e resultado negativo. No outro, esses três indicadores foram positivos. Em uma análise mais detalhada e isolada de cada um, constatou-se que a diferença foi devida à venda de animais enquanto em um ela representou 16,03\% da receita, em outro, foi apenas 3,34\% - o que pode ser observado pelo alto valor do desvio-padrão em relação à média apresentada na Tabela 3. Esses resultados corroboram os obtidos por Almeida Júnior et al. (2002), ao constatarem que a venda de animais excedentes contribuiu incisivamente para o melhor desempenho econômico na atividade leiteira.

A lucratividade foi de -27,47; -36,46 e -1,20\%, significando que para cada $\mathrm{R} \$ 100,00$ investidos, houve uma perda de $\mathrm{R} \$ 27,47 ; \mathrm{R} \$ 36,46$ de $\mathrm{R} \$ 1,20$, ao passo que a rentabilidade foi de 2,$35 ;-5,51$ e $-1,55 \%$, nos sistemas de criação em regime de pastejo, semiconfinados e confinados, respectivamente. Pela lucratividade, podese comparar com outros sistemas de produção de leite, analisando qual foi o mais lucrativo e, pela rentabilidade, pode-se comparar com atividades diferentes, mostrando a melhor opção de investimento, como, por exemplo, com a caderneta de poupança, que, no período de 18 meses, obteve uma taxa real de juros de 9\%. Nesse caso, a aplicação em caderneta de poupança teria sido melhor negócio para os pecuaristas.

Na Tabela 6 apresentam-se os custos médios de produção por quilograma de leite de 16 produtores agrupados em função tipo de sistema de criação, em um período de 18 meses. Verifica-se que os valores médios de venda de $\mathrm{R} \$ 0,38$; $\mathrm{R} \$ 0,39$ e $\mathrm{R} \$ 0,43$, para os sistemas de criação em regime de pastejo, semiconfinados e confinados, respectivamente, foram suficientes para cobrir as despesas operacionais efetivas e as variáveis em 
todos os grupos, exceto as variáveis no grupo em regime de pastejo; não sendo suficientes para cobrir integralmente os custos totais em nenhum dos três tipos de sistemas de criação.

Na Tabela 7 verificam-se os custos médios de produção por quilograma de "leite virtual" de 16 produtores, agrupados em função do tipo de sistema de criação, em um período de 18 meses. O termo "leite virtual”, criado por Lopes e Lopes (1999), significa a quantidade de leite, em $\mathrm{kg}$, resultante da conversão dos valores apurados com as vendas de animais e esterco. Esse valor pode ser tomado como referência para o produtor avaliar se a atividade leiteira como um todo, principalmente a cria e recria de animais, está sendo viável economicamente. Verifica-se que os valores médios de venda foram suficientes para cobrir as despesas operacionais totais (que envolvem as despesas efetivas, com depreciação e mão-de-obra familiar). As despesas referentes ao custo total (custo fixo e custo variável) não foram totalmente cobertas, evidenciando que parte do custo fixo, principalmente a remuneração do capital investido, não foi coberto.

Dentro do preconizado por Lopes (2003), considerando um custo operacional total do leite de $\mathrm{R} \$$ 0,42 (Tabela 6) e o valor de venda de $\mathrm{R} \$ 0,39$, no grupo sistemas de produção em semi-confinamento, a atividade leiteira não foi viável economicamente, pois o produtor teve um prejuízo de $\mathrm{R} \$ 0,03$ por $\mathrm{kg}$ de leite $(0,39-0,42)$. Nesse caso específico, produzir leite não foi uma atividade viável. Nesse custo operacional total de $\mathrm{R} \$ 0,42 / \mathrm{kg}$ de leite, foram computadas todas as despesas, inclusive as da criação das bezerras e demais categorias animais. Mas, nesse período, os produtores pesquisados venderam alguns animais. $\mathrm{O}$ software CU\$TO BOVINO LEITE, utilizado no processamento eletrônico dos dados desta pesquisa, realizou a conversão dos valores apurados com as vendas de animais em leite e calculou o custo operacional total do "leite virtual” que, nesse caso, foi de R\$ 0,37 (Tabela 7). Assim, quando se considerou a venda de animais, a atividade foi rentável em R\$ 0,02 por $\mathrm{kg}$ de leite $(0,39-0,37)$. Com esse resultado encontrado nesta pesquisa, verifica-se em algumas situações pode ser verdadeira a afirmação comum feita por muitos produtores de leite: "Produzir leite é mau negócio. O que é bom negócio são as crias. As crias sim, valem a pena”. Considerando-se os resultados encontrados nesta pesquisa, por meio dos quais se constata uma margem líquida positiva (Tabela 2), mesmo sendo o custo operacional total superior ao preço de venda (Tabela 7), confirmam-se a importância e aplicabilidade da estimativa do "leite virtual”.

TABELA 6 - Custos médios de produção, por quilograma de leite de 16 sistemas de produção agrupados em função do tipo de sistema de criação, em R\$ (período de 18 meses).

\begin{tabular}{lcccccc}
\hline \multirow{2}{*}{\begin{tabular}{c} 
Sistema de Criação \\
\multicolumn{1}{c}{ Descrição }
\end{tabular}} & \multicolumn{2}{c}{ Pastejo } & \multicolumn{2}{c}{ Semiconfinado } & \multicolumn{2}{c}{ Confinado } \\
\cline { 2 - 7 } & Média & DP & Média & DP & Média & DP \\
\hline Custo operacional total & 0,46 & 0,16 & 0,42 & 0,08 & 0,42 & 0,06 \\
Custo operacional efetivo & 0,31 & 0,14 & 0,32 & 0,08 & 0,39 & 0,08 \\
Custo total & 0,63 & 0,27 & 0,58 & 0,09 & 0,48 & 0,02 \\
Custo fixo & 0,23 & 0,19 & 0,22 & 0,08 & 0,08 & 0,06 \\
Custo variável & 0,39 & 0,13 & 0,36 & 0,08 & 0,40 & 0,08 \\
Preço médio de venda do leite & 0,38 & 0,02 & 0,39 & 0,02 & 0,43 & 0,00 \\
\hline
\end{tabular}

DP = Desvio-Padrão 
Efeito do tipo de sistema de criação nos resultados econômicos de sistemas de...

TABELA 7 - Custos médios de produção por quilograma de "leite virtual” de 16 sistemas de produção, agrupados em função do tipo de sistema de criação, em R\$ (período de 18 meses).

\begin{tabular}{lcccccc}
\hline \multicolumn{1}{c}{ Sistema de Criação } & \multicolumn{2}{c}{ Pastejo } & \multicolumn{2}{c}{ Semiconfinado } & \multicolumn{2}{c}{ Confinado } \\
\multicolumn{1}{c}{ Descrição } & Média & DP & Média & DP & Média & DP \\
\hline Custo operacional total & 0,30 & 0,12 & 0,37 & 0,07 & 0,38 & 0,08 \\
Custo operacional efetivo & 0,24 & 0,10 & 0,30 & 0,07 & 0,36 & 0,11 \\
Custo total & 0,43 & 0,23 & 0,52 & 0,10 & 0,44 & 0,06 \\
Custo fixo & 0,19 & 0,16 & 0,22 & 0,08 & 0,08 & 0,05 \\
Custo variável & 0,25 & 0,09 & 0,30 & 0,07 & 0,36 & 0,11 \\
Preço médio de venda do leite & 0,38 & 0,02 & 0,39 & 0,02 & 0,43 & 0,00 \\
\hline
\end{tabular}

DP = Desvio-Padrão

\section{CONCLUSÕES}

Diante dos resultados, concluiu-se que: a) o tipo do sistema de criação influenciou o custo total de produção do leite e, portanto, a lucratividade e rentabilidade, sendo os sistemas de produção em confinamento os que apresentaram os menores custos unitários; b) o tipo do sistema de criação influenciou os "pesos" dos itens componentes do custo operacional efetivo da atividade leiteira, sendo esses diferentes em cada um dos três sistemas estudados; c) a maior contribuição por parte da alimentação e mão-deobra já era esperada, confirmando-se os resultados de outros pesquisadores. No entanto, no item mão-deobra, percebe-se, de uma maneira geral, a necessidade de um melhor aproveitamento desse recurso, orientando os pecuaristas a aumentar a produção diária de leite por mão-de-obra permanente e também a relação número de animais por homem. (mão-de-obra); d) os valores obtidos na pesquisa com despesas referentes a medicamentos, principalmente vacinas e antiparasitários, bem como os referentes às despesas com materiais utilizados na ordenha ficaram bastante abaixo da média encontrada por outros pesquisadores. Tais fatos demonstram que um trabalho de educação e conscientização da importância da saúde animal, bem como da obtenção higiênica do leite, precisa ser realizado urgentemente com os produtores de leite da região de abrangência da pesquisa; e) esforços gerenciais e tecnológicos deverão ser feitos, objetivando aumentar a produção média diária, que está muito aquém do ponto de equilíbrio; f) na análise econômica, por apresentar margem líquida positiva e o resultado negativo, nos três tipos de sistemas de criação, conclui-se que a atividade leiteira tem condições de produzir em médio prazo; em longo prazo os pecuaristas estão se descapitalizando.

\section{REFERÊNCIAS BIBLIOGRÁFICAS}

ALMEIDA JÚNIOR, G. A. de; LOPES, M. A.; PINATTO, F. Efeito da venda de animais na rentabilidade de um sistema intensivo de produção de leite tipo B no estado de São Paulo. In: REUNIÃO ANUAL DA SOCIEDADE BRASILEIRA DE ZOOTECNIA, 39., 2002, Recife. Anais... Recife: [s.n.], 2002. CD-ROM.

BENEDETTI, E.; ARAÚJO, J. D.; PEREIRA, E. M.; COLMANET, A. L. Análise de custo de produção de leite tipo B, na fazenda Experimental do Glória/UFU no ano de 1998. Uberlândia: [s.n.], 2000. CD-ROM.

EMPRESA BRASILEIRA DE PESQUISA AGROPECUÁRIA. Preço por litro de leite " $\mathrm{C}$ " ao produtor e ao consumidor (MG). Disponível em: $<$ http://www.cngl.embrapa.br/indicadores/leitecpp.php>. Acesso em: 28 out. 2003. 
ESTEVES, S. N.; CAMARGO, A. C.; MANSANO, A.; NOVAES, N. J.; FREITAS, A. R. de.; TUPY, O.; MACHADO, R. Efeitos de tecnologias agropecuárias em estabelecimentos familiares com produção de leite na região de Muriaé/MG: II. rentabilidade econômica da produção de leite. Muriaé: [s.n.], 2002. CDROM.

FABRI JÚNIOR, M. A. Importância do produleite na eficiência técnico-econômica dos produtores do sul de Minas Gerais. 1996. 42 f. Dissertação (Mestrado em Administração) - Universidade Federal de Lavras, Lavras, 1996.

GOMES, S. T. Indicadores de eficiência técnica e econômica na produção de leite. São Paulo: FAESP, 1997. 178 p.

GOMES, S. T.; CASTRO, M. C. D.; TAVARES, M. S. Análise da influência da produtividade do rebanho no custo de produção de leite. Coronel Pacheco: CNPGL, 1989. 4 p. Comunicado Técnico.

JARRET, J. Produção de leite de qualidade. In: SIMPÓSIO INTERNACIONAL SOBRE PRODUÇÃO INTENSIVA DE LEITE, 3., 1997, Belo Horizonte. Anais... Belo Horizonte: FMVZ/USP, 1997. p. 34-45.

LOPES, M. A. Sistemas computacionais para cálculo do custo de produção do leite e carne. Lavras: FAEPE/PROEX, 2003. 35 p. Apostila.

LOPES, M. A.; ALMEIDA JÚNIOR, G. A.; CARVALHO, F. C. de; SOUSA, M.; RINO, M. C. P. B. Estudo da rentabilidade de um sistema de produção de leite tipo $B$ no estado de São Paulo. In: CONGRESSO BRASILEIRO DE ADMINISTRAÇÃO RURAL, 4., 2001, Goiânia. Anais... Goiânia: ABAR, 2001. CD-ROM.

LOPES, M. A.; CARVALHO, F. de M. Custo de produção do leite. Lavras: UFLA, 2000. 42 p. (Boletim Agropecuário, 32).

LOPES, M. A.; LOPES, D. de C. F. Desenvolvimento de um sistema computacional para cálculo do custo de produção do leite. Revista Brasileira de Agroinformática, [S.l.], v. 2, n. 1, p. 1-12, 1999.
LOPES, M. A.; CAMPELLO, R. de P.; CARVALHO, F. de M.; LOPES, D. de C. F. Custo Bovino Leite 1.0: software de controle de custos para a atividade leiteira. Revista Brasileira de Agroinformática, [S.l.], v. 4, n. 2, p. 102-115, 2002a.

LOPES, M. A.; LIMA, A. L.; REIS, R. P. Custos de produção de leite: um estudo de caso no sul de MG. In: CONGRESSO BRASILEIRO DE MEDICINA VETERINÁRIA, 24., 2002, Gramado. Anais... Gramado: SOVERGS, 2002b. CD-ROM.

MANZANO, A.; NOVAES, N. J.; CAMARGO, A. C. de; ESTEVES, S. N.; FREITAS, A. R. de; TUPY, O.; MACHADO, R. Avaliação de tecnologias agropecuárias em estabelecimentos familiares com produção de leite no município de São Carlos/SP: II. rentabilidade econômica da produção de leite. São Carlos: [s.n.], 2002. CD-ROM.

MARQUES, V. M. Custos e escala na pecuária leiteira: estudo de casos. 1999. 59 p. Dissertação (Mestrado em Administração Rural) - Universidade Federal de Lavras, Lavras, 1999.

MARTINS, M. C.; SILVA, V. N. O.; SILVA, J. A. B.; DIOGO, J. M. S.; SILVEIRA, M. A.; FRANCO, G. L. Análise econômica da produção de leite orgânico: um estudo de caso no Distrito Federal. Brasília, DF: [s.n.], 2002. CD-ROM.

MATSUNAGA, M.; BEMELMANS, P. F.; TOLEDO, P. E. N. de; DUlleY, R. D.; OKAWA, H.; PEDROSO, I. A . Metodologia de custo de produção utilizado pelo IEA. Agricultura em São Paulo, São Paulo, v. 23, n. 1, p. 123-139, 1976.

PEREIRA, P. L.; BENEDETTI, E.; GUIMARÃES, R. A. Avaliação técnica do modelo de produção de leite a pasto da fazenda experimental do Glória da FUNDAP/UFU, no ano agrícola 2000/ 2001. Uberlândia: [s.n.], 2002. CD-ROM.

PRADO, E.; CRUZ, F. E. R.; VIANNA, F. C.; TORRES, A. M. C.; REIS, D. L. Avaliação de desempenho técnico econômico de explorações leiteiras em Divinópolis-MG, segundo a forma de produção. Arquivo Brasileiro de Medicina Veterinária e Zootecnia, Belo Horizonte, v. 47, n. 3, p. 361-372, 1995. 
REIS, R. P. Como calcular o custo de produção. Lavras: Bioex-café, 1999a. 15 p. (Informativo Técnico do Café, 3).

REIS, R. P. Introdução à teoria econômica. Lavras: UFLA/FAEPE, 1999b. 108 p.

SCHIFFLER, E. A.; MÂNCIO, A. B.; GOMES, S. T.; QUEIROZ, A. C. de. Efeito da escala de produção nos resultados de produção de leite $B$ no estado de São Paulo. Revista Brasileira de Zootecnia, Viçosa, v. 28, n. 2, p. 425-431, mar./abr. 1999.

SEBRAE-MG/FAEMG. Diagnóstico da pecuária leiteira do estado de Minas Gerais. Belo Horizonte, 1996. $102 \mathrm{p}$. 